\section{Postgenomic histochemistry}

\author{
M.G. Manfredi Romanini \\ Dipartimento di Biologia Animale, Pavia, Italy
}

1 n my editorial covering the year 2001, I drew attention to "the torrency of information pouring out of the multiorganizational genome sequence projects into the field of active biological research». On that occasion I also expressed the opinion that this enormous quantity of data coming from genomics and proteomics had to be elaborated by resorting even to new models of cell activity, as for instance, models based on the role of transcripts.

The data from this postgenomic biology have to be compared, however, with the qualitative and quantitative data emerging today from the histochemical literature obtained from a variety of models and from the complexity of integrated morphological, submorphological, enzymo- or immunohistochemical in situ biological approaches which are the mainstays of the important refluorishing of the new histochemistry that our Journal has always supported. The objectives of this science are the molecular foundations of the function of the cell organelles, the coordinations among the different organelle activities in a cell, the rhythm of life of different cell populations and their correlation with different tissutal and extratissutal specialisations in humans, mammals, vertebrates, invertebrates and plants and finally bacteria and viruses during development under normal and pathological conditions (see Manfredi Romanini, 2002).

This first issue of 2003 has, therefore, to be read as a playout of these interests.

The first two papers of this issue are concerned with the recent molecular approaches in which changes in some structures (for instance, the cell membrane) may be interpreted as signals of specific pathogenesis. This is proved in the minireview by Maraldi et al., and in the following paper by Meola et al., both authors being interested in the molecular modifications of cell membranes in muscle pathologies: i.e. the nuclear envelophaties of Emery-Dreifuss muscular dystrophy and the hereditary skeletal muscle channelopathies, respectively

In the third paper, Royuela et al. give us an impressive series of data about the dystrophin- associated proteins in muscle cells and sciatic nerves (here the animal model is the cynomolgus monkey).

Modern basic cytology and cytochemistry with computational elaborations of fluocytometric data, and immunohistochemical and ultramicroscopic approaches are utilized in the paper by Smetana et al. on the role of the nucleoli in apoptotic mechanisms, and in the one by Echeverria et al. on the process of the $X Y$ bodies formation in the testis of rats and Guinea pigs.

A very different direction is followed by Croce et al. They added low and high molecular weight hyaluronate to adult human fibroblasts in a monolayer and achieved significant inhibition of cell growth. This inhibition was dependent on the hyaluronan concentration and independent of its molecular weight. They suggested that the utilisation of hyaluronan contributed to the three-dimensional organisation and the hydration of the extra-cellular matrix, influencing the cell environment and becoming a powerful modulator of fibroblast metabolism and growth.

A study on the aging process at the cell, tissue and organ level is presented by Franchini et al. in a very interesting model: the renowned hermaphrodite worm Caenorhabditis elegans. Besides a complete classical histochemical picture of the cell changes during the aging process, they discuss the progressive disorganization of the components of the gonad and point out the decrease of neurons positive to anticytokine and antigrowth factors. From an integrated analysis of different approaches to the different worm cellular types in aging, appears the important role of the nervous system as a central regulator of animal life span.

Another very different model, in the plant kingdom, is suggested by Pasqua et al., who describe the uptake of essential oils during root differentiation in Angelica archangelica L., a herbaceous biennial plant used in folk medicine, but mainly cultivated nowadays for its roots rich in oils used in flavouring perfumes (the angelica aroma). The authors prove that only the large secondary secretory ducts in the 
roots contain high concentration of $\alpha$ and $\beta$ phellandrene, important factors for the oil's aroma. This study is interesting, too, from a technical point of view: it shows splendid sections of roots at different developmental stages and proposes original stains (i.e. the nadi reaction which stains terpenic compounds violet) for in situ localization of oils.

I would like to add some information about the new edition of the Journal.

While the scientific board has not changed, Giovanni Meola will take the place of the late Guglielmo Scarlato on the Editorial Board, and Guido Rindi and Tindaro Renda have also been invited to be consulting specialists for histopathology.

As we have already announced in the last issue 2002, the European Journal of Histochemistry will be published under the auspices of the Ferrata Storti Foundation, Pavia, and has a new publisher, the Tipografia PIME Editrice, Pavia, who has assured us of a strong support in the promotion and the development of the image of our Journal in its relations with the media at all levels; all efforts will be made to further shorten the time of revision and publication of the papers. Our website has been renewed too, with the hope that good use will be made of it.

We shall be much obliged of your standing by us in our efforts to improve the Journal. Both suggestions and criticisms will be well received.

\section{References}

Croce MA, Boraldi F, Quaglino D, Tiozzo R, Pasquali-Ronchetti I. Hyaluronan uptake by in vitro adult human skin fibroblasts. Eur $J$ Histochem 2003; 47:63-74.

Echeverría OM, Ortiz Rand Vázquez-Nin GH. Ultrastructural and immunocytochemical analysis of the $X Y$ body in rat and Guinea pig. Eur J Histochem 2003; 47:45-54.

Franchini A, Peruzzi E, Ottaviani E. Morphochemical age-related changes in the nematode Caenorhabditis elegans: immunoperoxidase localization of cytokine- and growth factor-like molecules. Eur J Histochem 2003; 47:75-80.

Maraldi N M, Lattanzi G, Sabelli P, Ognibene A, Columbaro M, Capanni C, Rutigliano C, Mattioli E, Squarzoni S. Immunocytochemistry of nuclear domains and Emery-Dreyfuss muscular dystrophy pathophysiology. Eur J Histochem 2003; 47:3-16.

Manfredi Romanini MG. The year of encroaching genomics. Eur J Histochem 2001; 45:5-6.

Manfredi Romanini MG. Histochemistry: work in progress. Eur J Histochem 2002; 46:289-92.

Meola G, Sansone V, Rotondo G, Mancinelli E. Muscle biopsy and cell cultures: potential diagnostic tools in hereditary skeletal muscle channelopathies. Eur J Histochem 2003; 47:17-28.

Pasqua $G$, Monacelli $B$, Silvestrini A. Accumulation of essential oils in relation to root differentiation in $A$. archangelica $L$. Eur $J$ Histochem 2003; 47:87-90.

Royuela M, Chazalette D, Rivier F, Hugon G, Paniagua R, Guerlavais V, Fehrentz JA, Martinez J, Mornet D. Dystrophin and dystrophinassociated protein in muscles and nerves from monkey. Eur $\mathrm{J}$ Histochem 2003; 47:29-38.

Smetana K, Hrkal Z. Nucleoli in large (giant) bi- and multi-nucleated cells after photodynamic treatment inducing the apoptotic process. Eur J Histochem 2003; 47:39-44. 